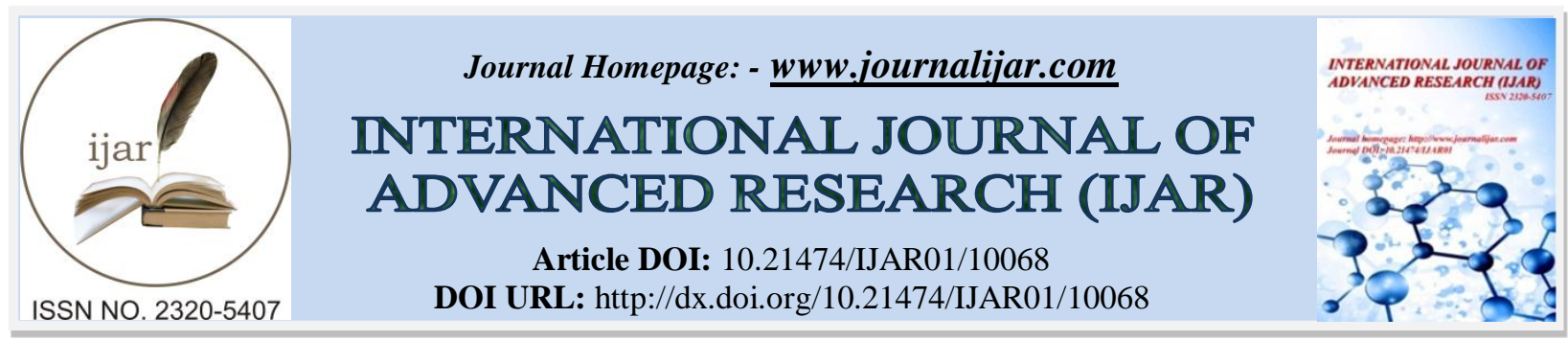

RESEARCH ARTICLE

\title{
THE PRACTICALITY OF INTEGRATED SCIENCE TEACHER BOOKS USING INTEGRATED TYPE WITH THE THEME OF ADAPTATION OF THE HUMAN BODY TO CHANGES IN TEMPERATURE INTEGRATED $21^{\text {ST }}$ CENTURY LEARNING.
}

\author{
Aprili Samra $^{1}$, Toni Supriadi ${ }^{2}$, Ratnawulan ${ }^{2}$ and Syafriani ${ }^{2}$. \\ 1. Smpn 3 talamau, west sumatera, Indonesia. \\ 2. Department of Physics, Faculty of Mathematics and Natural Sciences, Padang.
}

\section{Manuscript Info}

\section{Manuscript History}

Received: 12 September 2019

Final Accepted: 14 October 2019

Published: November 2019

Key words:-

Teacher's Book, Adaptation of the human body to change in temperature, $21^{\text {st }}$ Century Learning.

\begin{abstract}
This study aims to determine the practicality of integrated science teacher books integrated type with the theme of adaptation of the human body to temperature changes that are integrated with 21 stcentury learning. The method used is a plomp development model in which this model has 3 stages. The research is limited to the prototype stage. Data collection is done through interviews. The questions asked were about concept maps, materials, integration of lonsor land material, learning activities, and examples of assessments contained in the teacher's book. According to the teacher, the concept map contained in the teacher's book illustrates all the material to be studied. Teacher books produced and tested in the field obtained a valid and practical teacher's book.
\end{abstract}

Copy Right, IJAR, 2019,. All rights reserved.

\section{Introduction:-}

Science learning is the study of events that occur in nature by observing, experimenting, inferring, preparing theories so that students have organized knowledge, ideas and concepts about the natural environment, which is obtained from experience through a series of scientific processes. In this world many are filled with products from the results of scientific investigations, therefore everyone has the right to be directly involved in solving technological and scientific problems. Science learning requires advanced skills, which require people to be able to learn, reason, think creatively, make decisions, and solve problems. (National Research Council: 1996)

Natural science subjects are closely related to natural phenomena and their application in everyday life. Pudjiaji (2013) in the Ministry of Education and Culture (2017: 16) Natural Science is defined as a collection of knowledge about objects and natural phenomena obtained from the results of the thoughts and investigations of scientists conducted with experimental skills using scientific methods. Puskur (2013) in Muschen (2016: 1) says the nature of science includes four elements, namely attitudes, processes, products and applications. In learning science, the four elements must work together to prepare a generation that realizes the importance of science so that they think logically, critically, creatively and can communicate properly. The learning process in the 2013 curriculum uses a scientific approach. The Ministry of Education and Culture (2010) in Asri (2017:4) provides its own conception that the scientific approach (scientific approach) in learning includes components: observing, asking, reasoning, trying or creating, presenting or communicating.

Corresponding Author:-Ratnawulan.

Address:- Department of Physics, Faculty of Mathematics and Natural Sciences, Padang. 
The science learning process is carried out with integrated learning, in carrying out integrated science learning the educator uses techniques and methods, one of which is through the type of learning. The type of learning applied must be adjusted to the learning material. According to Fogarty (1991), there are ten ways or models in planning integrated learning. The ten ways or models are: (1) fragmented, (2) connected, (3) nested, (4) sequenced, (5) shared, (6) webbed, (7) threaded, (8) integrated, (9) immersed, and (10) networked. The integrated model is a model used by researchers because it is considered suitable to integrate the concepts of inter-field science studies and is easy to emulate and apply in the learning process. With this integration, students will gain full knowledge and skills, so that learning becomes meaningful for students. Meaning here gives the meaning that in integrated learning students will be able to understand the concepts they learn through direct and real experience that links between concepts in intra subjects and between subjects and is a learning approach that can train students' critical thinking skills. The main concern in implementing the integrated type is the foresight in identifying and setting indicators that will be mapped on subjects that will be combined to produce a theme. Integration in learning science can be done if various studies of science are put together or combined into a single unit by using integrated science learning themes that require science teachers who are professional masters of science materials in an integrated manner (physics, chemistry, biology), able to package and develop material in the form of themes or topics by using adequate facilities and infrastructure. Therefore, the application of the integrated type learning model at school is expected to be able to facilitate teachers and students in the teaching and learning process so that the expected learning objectives can be achieved.

Teacher's book is a guide for teachers in carrying out classroom learning, this is in accordance with the Minister of Education Regulation No. 51 of 2014 in Article (1) paragraph 1 explained that "set textbooks as student books and teacher manuals for primary and secondary education". According to Susanti (2017: 6) basically, the teacher's book is a unity that cannot be separated as an explanation of the activities that must be carried out on the student's book. This is in line with Government Regulation No. 13 of 2015 contained in the article (1) paragraph 22, The teacher's manual is a guide that contains learning strategies, learning methods, learning techniques and assessments for each subject and / learning theme.

The teacher's book talks about problems with the process in the classroom, which is used as a guide for the use of student books. Therefore the teacher must first learn information from the teacher's book, which is the reference order of subject matter developed from the graduate competency standards, core competencies, and basic competencies of each lesson content. Then it is combined in one particular theme, a network of themes from each theme which contains the basic competencies and indicators of each content charge that must be achieved.

The fact of Integrated Science learning in the field, currently the majority of teacher books used by teachers in SMP Pasaman Barat District including SMPN 3 Talamau are books published by the curriculum centre and books of the ministry of education and culture. Based on observations at school it was found that the teacher's book at the junior secondary level had been compiled in an integrated manner that refers to the 2013 curriculum. According to (Mumun, 2014) in line with the implementation of the 2013 curriculum, the science subjects in junior high were initially divided into 3 subjects namely Physics Biology and Chemistry become a unified form of integrated science. Therefore, a teacher's book is needed which covers 3 subjects. However, if reviewed further, there are still some obstacles in the field, especially in terms of the delivery of subject matter. For teachers with a physics, the background will have difficulty when explaining biological material, and vice versa biology teachers will have difficulty when explaining physics material. This is due to the revised edition of the seventh-grade class book published by the government for a brief explanation of the material for teachers so that teachers lack information, which makes the expected competencies difficult to achieve.

Of the various problems found in the field, there are several solutions that can help solve these problems. One solution is to make an Integrated Science Teacher's Book an integrated type of integrated 21st-century learning that encourages students to be active and support the ability and creativity of teachers in designing and implementing learning. Therefore, the researcher plans to develop learning support facilities in the form of a junior high school science teacher's book on the theme of the human body's adaptation to temperature changes with integrated learning integrated type 21st century learning that will help teachers in the learning process. With the teacher's book, expected to be guides and teachers handle in the learning process in accordance with the basic competencies that must be mastered, learners. 


\section{Research methods:-}

Development research using the Plomp development model consists of 3 stages, namely: 1) preliminary research (preliminary analysis) 2) prototyping phase (design phase) 3) assessment phase (Plomp, 2013). The model chosen is adjusted to the characteristics faced in the field. This model was chosen because it has several advantages including (1) is more appropriate to be used for the development of textbooks (2) a complete and systematic description (3) before being tested, the textbooks that will be developed are revised by themselves and consulted with experts/experts, and (4) individual and small group evaluations. Based on input from experts, the device was revised, an individual or small group evaluation was carried out, then it was tested on the chosen school when tested the use and implementation of the textbook were tested. After the textbook was revised based on teacher or observer input, it was continued with trials in the next school. In the final process, responses from teachers are asked and their effectiveness is tested regarding the use of student books for teachers. Procedure for developing integrated science books for integrated type students with the theme of adaptation of the human body to changes in temperature in integrated 21st-century learning.

\section{Research result:- \\ Evaluation One To One}

One-to-one evaluation is done by asking the teacher to comment on the teacher's book that has been designed. The teacher's book was given to 5 teachers who taught in junior high schools in West Pasaman. The teacher is asked to read the teacher's book with the aim to get input from the teacher about the lack of books and the teacher's desire for the teacher's book that was developed.

Data collection is done through interviews. The questions asked were about concept maps, materials, integration material, learning activities, and examples of assessments contained in the teacher's book. According to the teacher, the concept map contained in the teacher's book illustrates all the material to be studied.

Furthermore, the material in the teacher's book is clear and easy to understand, but implementation in learning can be done in enrichment. The integration of the adaptation of the human body to changes in temperature can add to the teacher's insight. Learning activities contained in the teacher's book are easy to understand and can be implemented. In addition, examples of assessments contained in the teacher's book are easy to understand and discussion of the questions contained in the teacher's book are in accordance with the questions in the student's book.

The colour composition aspect of the teacher's book makes the teacher interested to read it. Integration of enrichment material adaptation of the human body to changes in temperature in the teacher's book can add to the teacher's insight. The completeness of information both learning activities and assessments in the teacher's book makes it easier for teachers to carry out learning.

In terms of efficiency, according to the teacher, the time needed to understand the teacher's book is not too long. The teacher's book can be used in the learning process and can be used as additional information for the teacher. Overall the teacher's book is easy to understand, interesting, and efficient.

\section{Evaluation of Small Group}

The small group physics teacher's book trial was conducted after the evaluation was completed one by one, this evaluation was the stage that was carried out before entering the field test stage. At this stage, the researchers conducted a trial on 1 teacher from SMP N 1 Talamau, and 1 teacher from SMP N 2 Talamau and 1 teacher from SMP N 3 Talamau.

Test the practicality of teacher books on small group evaluations using teacher response questionnaires. The practicality questionnaire of the teacher's book includes the following matters: (a) easy to understand in terms of mind maps, material available in the teacher's book, material adaptation of the human body to changes in temperature, and learning activities, (b) interesting in terms of the composition of the color of the teacher's book , material adaptation of the human body to changes in temperature adds to the reader's insight, and the completeness of the material in the teacher's book adds to the reader's information, (c) efficient in terms of relative time in understanding the teacher's book, in accordance with the standard school hours set by the government, in terms of book costs teachers can be prepared and developed for a relatively small cost, teacher books can be used as a source of additional teaching materials for teachers, and teacher books can be used to facilitate teachers in the learning 
process. There are 16 indicators for the practicality of teacher responses. The results of the teacher's practicality test results of each of these statements are presented in Table 1.

Table 1:-Teachers Respond to Small Group Tests on Teacher's Book

\begin{tabular}{|l|l|l|l|}
\hline No & Statement & Value & Category \\
\hline 1 & Easy to understand & 76,39 & Practical \\
\hline 2 & Interesting & 79,17 & Practical \\
\hline 3 & Efficient & 77,08 & Practical \\
\hline
\end{tabular}

Based on Table 1 it can be seen that the level of practicality of the teacher's book from the easily understood and efficient aspects is in the very practical category, while the interesting aspect is in the practical category. This teacher is interesting to learn. While the highest value is in the statement of the material in the teacher's book is clear and easy to understand. Furthermore, based on the results of practicality for the small group test carried out a revision of the interesting aspects, so that the material in the teacher's book is more complete and interesting to learn. After revision, proceed to the large group test (field test).

\section{Field Test}

Prototype III (field trial) was conducted at the SMPN 3 Talamau teacher and the West Java Teachers Teachers MGMP in West Pasaman. Test the practicality of the teacher's book using the teacher's response questionnaire. The practicality questionnaire of the teacher's book includes the following things: (a) easy to understand in terms of mind maps, material in the teacher's book, material adaptation of the human body to changes in temperature, and learning activities, (b) interesting in terms of the composition of the color of the teacher's book, material adaptation of the human body to changes in temperature adds to the reader's insight, and the completeness of the material in the teacher's book adds to the reader's information, (c) efficient in terms of relative time in understanding the teacher's book, in accordance with the standard school hours set by the government, in terms of book costs teachers can be prepared and developed for a relatively small cost, teacher books can be used as a source of additional teaching materials for teachers, and teacher books can be used to facilitate teachers in the learning process. There are 14 indicators of practicality in teacher responses. The results of the teacher's practicality test for each statement are presented in Table 2.

Table 2:-The practicality of Field Test on Teacher's Book

\begin{tabular}{|l|l|l|l|}
\hline No & Statement & Value & Category \\
\hline 1 & Easy to understand & 76,39 & Practical \\
\hline 2 & Interesting & 77,43 & Practical \\
\hline 3 & Efficient & 77,08 & Practical \\
\hline
\end{tabular}

Based on Table 2 it can be seen that the practicality of the teacher's book from the easily understood aspect obtained a value of 76.39 in the practical category, from the aspect of attractiveness obtained 77.43 in the practical and efficient category obtained 77.08 in the practical category.

\section{Discussion:-}

\section{The practicality of Teacher's Books}

The practicality test of teacher's books is conducted by the teacher. Obtaining practicality data obtained from the results of the practicality questionnaire filled out by the teacher. The practicality test is carried out through three stages, one-on-one evaluation stages, small group evaluations, and field tests.

One-to-one evaluation is done by asking the teacher's comments about the teacher's book that was developed. The teacher's book was given to 5 teachers who taught at the Middle School in West Pasaman. Data obtained from the questionnaire results in the form of questions filled out by the teacher. The results of one-on-one evaluations, overall the physics teacher's book is easy to understand, interesting and efficient. The material in the teacher's book is easy to understand. The learning activities in the teacher's book make it easy for the teacher to carry out the learning process. The aspect of colour composition in the teacher's book makes the teacher interested in reading the teacher's book. In terms of efficiency, the time needed for the teacher to understand the teacher's book is not too long and the teacher's book can be used in the learning process. After the one-on-one evaluation, a small group evaluation is continued. 
The small group test results obtained the practicality of the teacher's book in the practical category. From the aspect of easy to understand with practical categories, this shows that the concept map, learning material, learning activities and learning assessment contained in the teacher's book are easy to understand. The practicality of teacher's books from interesting aspects with practical categories. This shows that the colour composition in the teacher's book is interesting to read. Furthermore, from the efficient aspects of the teacher's book with practical categories. This shows that the time needed to understand the teacher's book is not too long. Teacher's books can be used to facilitate teachers in carrying out learning. Based on the results of a small group test of aspects of attractiveness, the use process, the ease of use and the time of use made it can be concluded that the integrated physics science teacher's book Integrated Integrated Type with the Theme of Human Body Adaptation Systems Against Temperature Changes Intimated 21st Century Learning is already practical.

The lowest practicality value is the completeness of the material with a value of 75 . This shows that the completeness of the material in the teacher's book has not been interesting to learn. This is due to the fact that the material in the teacher's book is still incomplete and the integration of the drought material is separate. The results of the product revision were tested on a field test.

After a revision based on the advice of a small group then proceed with a field test. The field test was conducted at SMPN 2 Talamau and MGMP IPA of West Pasaman Regency. The practicality of the teacher's book is seen from the interesting, efficient and easily understood teacher's book. Through the field test, the practicality of the teacher's book is obtained from the aspect of easily understood with practical categories. This shows that the concept map, learning material, learning activities and learning assessment in the teacher's book are easy to understand. The practicality of teacher's books from interesting aspects with practical categories. This shows an increase in practicality after being revised, namely by improving the suggestion of evaluating small groups about the completeness of the material contained in the teacher's book is not interesting to study. The material in the teacher's book has been adapted to the learning indicators and the integration of the material is explained according to the learning indicators. After the revision, the completeness of the material in the teacher's book is interesting to learn and adds insight and information for the reader.

Furthermore, from the efficient aspects of the teacher's book with practical categories. This shows that the time needed to understand the teacher's book is not too long. Teacher's books can be used to facilitate teachers in carrying out learning. Based on the field test results of the aspects of attractiveness, the use process, the ease of use and the time taken, it can be concluded that the integrated science teacher book Integrated type with the theme of the human body's adaptation system to changes in temperature is 21 st-century learning with practical categories. This can be seen from the easy and interesting teacher books that are developed that cannot be separated from the combination of illustrations and the use of familiar languages. Ngabekti et al (2018) state that clear and precise illustrations and familiar language styles really help facilitate the reader in using teaching material. Gustria (2019) in his research stated that the ease of use of teaching materials that were developed as an important factor in the practicality of teaching material. According to Fauzan (2002) practicality is looking at the extent to which (teacher/student) and other experts consider interventions whether a product is interesting and can be used in normal conditions. Asrizal et al (2018) state that practicality shows how usefulness, attractiveness and ease of teaching materials are used in the learning process.

\section{Conclusion:-}

Based on the measurement results of the practicality of integrated science teacher books integrated a type of adaptation theme of the human body to changes in temperature integrated learning 21 st century. It was concluded that the teacher's book produced practically used to improve the ability of 21 st-century students.

\section{References:-}

1. Fogarty, Robin. 1991. How to Integrated the Curricula. Palatine, Ilinois : IRI/Skylight Publishing, Inc.

2. Gravemeijer, K. (2012). Aiming for 21st century skills. Proceedings of the Commission Internationale pour l'Etude et L'Amelioration de l'Enseignement des Mathematiques (CIEAEM 64): Mathematics education and democracy: Learning and teaching practices, 30-43.

3. OECD. (2016). Country Note - Result from PISA 2015 Indonesia (Paris: OECD Publishing)

4. OECD. (2016). PISA 2015 Assessment and Analytical Framework (Paris: OECD Publishing) 
5. Gusnedi, G., Ratnawulan, R., \& Triana, L. (2018, April). Application of Student Book Based On Integrated Learning Model Of Networked Type With Heart Electrical Activity Theme For Junior High School. In IOP Conference Series: Materials Science and Engineering (Vol. 335, No. 1, p. 012132). IOP Publishing.

6. Rahmiwati, S. (2018, April). The Implementation of Integrated Natural Science Textbook of Junior High School be Charged on Character-based Shared Models to Improve the Competence of Learners' Knowledge. In IOP Conference

7. Aprili Samra, Ratnawulan, Gusnedi. (2018) Analysis of Teachers Needs In Developing Integrated Science Textbook IPA Adaptation System Human Body To Temperature Change Using Integrated 21 st Century Learning.Conference Prosiding. ICRLP 2018

8. Toni Supriadi, Ratnawulan (2018). Identification Characteristics of Student in the Development of Integrated Natural Science Student Books Integrated 21th Century Learning: A Case Study in SMP N 3 Talamau West Pasaman.Conference Prosiding. ICRLP 2018. 